\title{
Margaret McCartney: Are GPs specialists in life?
}

\author{
Margaret McCartney general practitioner
}

Glasgow

"I understand dark clouds, but I'm not a meteorologist . . . I understand addiction, but I'm not a rehab counsellor." So run some of the quotes from a selection of well groomed GPs featured in a multimedia campaign by the Royal Australian College of General Practitioners. ${ }^{1}$

The campaign has been ongoing in the context of intense funding pressure and in election season, and the college is trying hard to explain what it is that GPs do. One of the posters says, "I'm not just a GP. I'm your specialist in life."

A specialist in life? Able to advise on clothing choices, holiday destinations, good sexual partners, great opera, and excellent gin? I'm good at only some of those, and my evidence is all anecdotal—so, while I like the idea, I think not.

This looks to me like mission creep of the kind that potentially medicalises normal life. It also looks like an attempt to explain the almost unexplainable: what it is that GPs actually do.

As a GP, I'm a community evidenceologist—practising, I hope, honest pragmatism between the many gaps. Generalism is the specialism and uncertainty the currency, with undifferentiated symptoms, along with possible symptoms and doubt as the stock-in-trade.

Continuity, which general practice usually hides under its collective bushel, has kept healthcare's increasingly impossible balance of resources working

Without question, we need specialists, also sometimes mischievously defined as "exclusionists," who "do" only one organ or system and no more. But it's to our cost that we become slightly obsessed with expertise and excellence and not honest enough about the pressing challenge to ensure that everyone gets good enough care, rapidly enough, to start with. Generalists are the folk to do that, for generalism also means equity and access.

And generalism gives a better chance of continuity. This is the turbocharged dazzle that general practice usually hides under its collective bushel and has so far kept healthcare's increasingly impossible balance of resources working. If you have a chance to know and understand the person, the family, the environment, and the culture, there's a real chance of a professional relationship doing something useful throughout your lifetime's work.

The Australian college has another advertisement for GPs, which is remarkable ${ }^{2}$ - it shows a GP at work in fresh qualification, then in his middle and older age, as stories unfold about the families he looks after.

Maybe the real definition of a generalist is a "continuist": no matter what the problem, I will know and be able to appreciate how it fits in with everything else.

\section{Competing interests: See www.bmj.com/about-bmj/freelance- contributors/margaret-mccartney.}

Provenance and peer review: Commissioned; not externally peer reviewed.

Follow Margaret on Twitter, @mgtmccartney

My Health Career. Specialist in Life campaign for GPs. 14 Jan 2017. https://www. myhealthcareer.com.au/medicine/specialist-in-life-campaign.

2 Royal Australian College of General Practitioners. The good GP (cinema advertisement) 14 Jun 2015. https://www.youtube.com/watch?v=VD_xh428Fq0.

Published by the BMJ Publishing Group Limited. For permission to use (where not already granted under a licence) please go to http://group.bmj.com/group/rights-licensing/ permissions 